\title{
Hot weather increases competition between dairy cows at the drinker
}

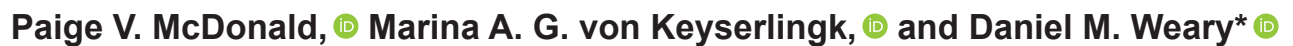 \\ Animal Welfare Program, University of British Columbia, 2357 Mall, Vancouver, BC, Canada, V6T 1 Z4
}

\begin{abstract}
Heat-stressed dairy cows on pasture will compete for resources that aid cooling, but it is not known how heat stress affects the competition for water by indoorhoused cows. The aim of this observational study was to evaluate how heat stress affects the behavior of indoorhoused cows at the drinker at both group and cow levels. For 3 wk after calving, cows were housed in a dynamic group of 20 animals in a pen with 12 electronic feed bins, 2 electronic water bins, and 24 freestalls. A total of 69 lactating Holstein dairy cows were enrolled over the 59-d study. The electronic water bins recorded time spent at the drinker, frequency of visits, water intake, and competitive events for $24 \mathrm{~h} / \mathrm{d}$. Competitive events were quantified using the number of replacements (recorded when there was a $\leq 29$-s interval between 2 cows sequentially visiting the same drinker). The number of replacements a cow was involved in was used to determine her level of competitive success at the drinker (low, medium, high). The temperature-humidity index (THI) was recorded by the local weather station, and moving averages for daily maximum THI over a 3-d period were calculated. For the analysis of time spent at the drinker, frequency of visits, and water intake, the measures from all cows were averaged to create 1 observation per day, and the number of replacements at the drinker was summed. A linear regression was performed to determine the relationship between THI and group-level drinking behavior. At the cow level, a repeated measures mixed model, with fixed effects of level of competitive success, milk yield, and 3-d maximum THI and a first-order autoregressive covariance structure, was used to determine how increasing THI affects the drinking behavior of individual cows based on their level of competitive success. Feed intake was included as a fixed effect in the water intake model. We found that, with increasing THI, cows drank more water, spent more time at the drinker, made more visits to the drinker, and engaged in more competitive
\end{abstract}

Received August 14, 2019.

Accepted November 18, 2019.

*Corresponding author: dan.weary@mail.ubc.edu events at the drinker. In exploratory analysis, we found that cows with low competitive success at the drinker shifted their drinking behavior to avoid the drinker at the hottest and most competitive time of day. These results indicate that behavior can be used to indicate when cows feel hot. These measures may be of practical value in deciding when to provide cooling, especially for farms where attendance at the drinker can be monitored electronically.

Key words: heat stress, aggressive behavior, water intake, social rank

\section{INTRODUCTION}

Heat stress occurs when heat load, accumulated both metabolically and from the environment, is higher than the animal's ability to dissipate this heat (Bernabucci et al., 2010). The risk of heat stress in dairy cows is commonly assessed with the temperature-humidity index (THI), which represents climatic conditions based on air temperature and relative humidity $(\mathbf{R H}$; Bernabucci et al., 2014). Heat stress was thought to occur when the THI exceeded 72 (Armstrong, 1994), but more recent work has shown that dairy cows begin to experience heat stress at a THI of 68 (Zimbelman et al., 2009). Heat stress can lead to decreased milk yield (Bouraoui et al., 2002), low fertility (Biffani et al., 2016), increased standing time (Allen et al., 2015), and decreased feed intake and increased water intake (Beatty et al., 2006).

Agonistic social behavior, such as competition, can occur over resources that aid in cooling (Vizzotto et al., 2015), such as seeking shade and increasing water intake (Dash et al., 2016). Schütz et al. (2010) found that dairy cows will engage in aggressive interactions to gain access to shade and, when not provided with shade, spend more time standing within $4.5 \mathrm{~m}$ of the water trough. Dairy cows will also compete for proximity to a water source (Vizzotto et al., 2015). Coimbra et al. (2012) found that more agonistic interactions occurred during warmer hours; however, although data were collected on agonistic interactions at various resources, the results were not reported separately for the number of events that took place over access to water. These 
studies were all conducted with dairy cows on pasture. Competition for water has yet to be studied in indoor housing despite aggression being more common indoors (O'Connell et al., 1989).

Competition over resources can be detrimental to cows by, for example, reducing the number of times that cows are able to visit the feeder (DeVries et al., 2004) and the amount of time spent feeding (Olofsson, 1999). Not all cows experience these negative effects equally; cows with lower social rank are disproportionally affected by competition (Olofsson, 1999; DeVries et al., 2004; Proudfoot et al., 2009). During competition at the feed bunk, cows of lower social rank lose more feeding time than dominant cows (Olofsson, 1999), eat faster (Proudfoot et al., 2009), and avoid the feed bunk at peak times of day (Olofsson, 1999; DeVries et al., 2004). Although not studying the direct effects of competition due to elevated ambient temperature, Coimbra et al. (2012) found that dominant cows were able to monopolize a water trough when it was located in a narrow (and presumably more easily defensible) corridor versus when it was located in an open paddock. It is unknown how social rank affects drinking behavior and competition at the drinker during heat stress.

This observational study addresses objectives at both the group and cow levels. Our objective at the group level was to describe the association between increasing THI and behavior of indoor, loose-housed dairy cows at the drinker, with particular attention to competition for this resource. Our objective at the cow level was to describe the relationship between THI and drinking behavior of individual cows based on their level of competitive success at the drinker. We predicted that (1) periods with high THI would lead to increased water intake, frequency of visits to the drinker, time spent at the drinker, and competitive events at the drinker and (2) that cows with lower levels of competitive success at the drinker would be most affected. We also explored how the distribution of drinking behavior throughout the day differed for cows with different levels of competitive success at the drinker.

\section{MATERIALS AND METHODS}

\section{Animals and Housing}

All procedures were approved by the University of British Columbia Animal Care Committee (protocol A14-0040). Data were collected from June to August 2014 at the University of British Columbia Dairy Education and Research Center (Agassiz, BC, Canada) as part of a larger study by Neave et al. $(2017,2018)$ and Lomb et al. (2018a,b). The barn was a passively ventilated $2,230-\mathrm{m}^{2}$ wood frame building with 4 rows of freestalls consisting of 120 stalls divided into 10 pens of 12 stalls each (5 pens on each side of the building separated by a center feed alley). The side walls (facing northwest and southeast) had a 1.2-m concrete wall with $1 \mathrm{~m}$ of open space above. The end walls (facing northeast and southwest) were open. This barn design was typical of farms in this region.

A total of 69 lactating Holstein dairy cows (with a mean \pm SD parity of $2.6 \pm 1.7$ and a range of 1 to 9 lactations) were followed. Average $( \pm \mathrm{SD})$ milk production was $38.1 \pm 12.0 \mathrm{~kg} / \mathrm{d}$ ( range $=4.0-66.0 \mathrm{~kg} / \mathrm{d}$ ). Animals were housed together in a mixed-parity group for 3 wk after calving, except for 8 cows (mean \pm SD DIM of $231 \pm 124.0 \mathrm{~d}$ ) used as "filler" cows to maintain group size. Group size was kept constant at 20 animals, but group composition was dynamic, with cows entering the pen within $24 \mathrm{~h}$ after calving and leaving approximately $21 \mathrm{~d}$ later. The pen was equipped with 12 Insentec (Marknesse, the Netherlands) feed bins, 2 Insentec water bins, and 24 freestalls with pasture mats (Pasture Mat, Promat Inc., Woodstock, ON, Canada) covered with $5 \mathrm{~cm}$ of sand bedding. The pen did not have any form of heat abatement. Animals had ad libitum access to water and were milked and fed twice per day at approximately 0700 and $1700 \mathrm{~h}$ and 0800 and $1600 \mathrm{~h}$, respectively. Feed was formulated according to NRC (2001) guidelines.

\section{Drinking Behavior and Social Competition Measures}

Insentec water bins (Roughage Intake Control system) were used to continuously monitor drinking behavior and social competition. Each cow was fitted with an electronic ear tag (High Performance ISO Half Duplex Electronic ID Tag; Allflex Inc., St. Hyacinthe, QC, Canada), which the Insentec system used to allow and record individual access to each of the drinkers (for a full description and validation of the system, see Chapinal et al., 2007). Measures included water intake, frequency of visits to the drinker, and time spent at the drinker. To determine whether drinking behavior was affected by feeding behavior, the Insentec feed bins were also used to continuously monitor feed intake.

Social competition at the drinker was recorded using the concept of competitive replacements. A replacement is defined as when physical impact from one cow (actor) results in the recipient cow (reactor) withdrawing her head from the drinker, with the actor then taking the place of the reactor at the drinker. Physical impact is normally assessed via video analysis, but in the current study, replacements were identified with an algorithm that used data from the electronic drinking system to identify cases where the interval between 2 cows sequentially drinking from the same drinker was 
$\leq 29$ s. This method of quantifying social competition was validated by McDonald et al. (2019) for identifying replacements at the drinker with high sensitivity and specificity. Cows in the current study were kept under the same housing conditions as cows in this validation study.

The level of competitive success of each cow was determined from an index of success in competitive interactions at the drinker, as described by Galindo and Broom (2000). This index ranges from 0 to 1 and is calculated by dividing the total number of replacements in which the cow was an actor by the total number of replacements in which she was an actor or reactor. Cows with an index $<0.4$ were classified as having low success, those with an index $\geq 0.4$ and $\leq 0.6$ were classified as having medium success, and those with an index $>0.6$ were classified as having high success.

\section{Temperature and Humidity Measures}

Temperature and $\mathrm{RH}$ were recorded continuously at 1-h intervals by the Environment Canada weather station situated approximately $500 \mathrm{~m}$ from the barn. Hourly THI was calculated using the following formula, with temperature measured in ${ }^{\circ} \mathrm{C}$ and $\mathrm{RH}$ measured in $\%$ (NRC, 1971):

$$
\begin{aligned}
\mathrm{THI}= & (1.8 \times \text { temperature }+32)-[(0.55-0.0055 \\
& \times \mathrm{RH}) \times(1.8 \times \text { temperature }-26)] .
\end{aligned}
$$

\section{Statistical Analysis}

All statistical analyses were conducted in SAS (version 9.4; SAS Institute Inc., Cary, NC). Values reported are means \pm standard error unless otherwise noted. Adjusted coefficient of determination values are presented to account for the number of effects in the models.

Group-Level Drinking Behavior. For the grouplevel analysis, day was used as the observational unit (n $=63$ ). Four days were excluded due to pen disturbances, leaving $59 \mathrm{~d}$ in the analysis. For the analysis of drinking behavior (time spent at the drinker, frequency of visits to the drinker, water intake), measures from all cows in the pen $(\mathrm{n}=20)$ were averaged to create 1 observation per day. For the analysis of social competition at the drinker, the number of replacements was summed from all cows in the pen $(n=20)$ to create 1 observation per day. As dairy cows show a time lag in their response to heat stress (West et al., 2003), and following Hill and Wall (2017), who found that weather averaged over 3 $\mathrm{d}$ explained feed intake better than current-day or 7-d means, we calculated moving averages for daily mean and maximum THI over a 3 -d period (weather spanning the day behavior was measured plus the previous $2 \mathrm{~d}$ ).

A linear regression was performed to test the predictive value of THI on behavior at the drinker. Plots of residuals were examined to ensure approximate normal distribution and determine whether transformations of the data were required. The 3 - $\mathrm{d}$ moving averages of mean and maximum THI were compared to determine which THI parameter had the best fit. The best-fitting model was chosen as the one with the lowest Akaike information criterion (AIC), where a change in AIC of $\geq 4$ from the model with the minimum information criteria was considered a meaningful difference (Burnham and Anderson, 2001). Quadratic models were fitted for all dependent variables (time spent at the drinker, time spent at the drinker per visit, frequency of visits to the drinker, number of competitive replacements) by adding a squared term of the independent variable (THI), except for water intake, where a linear model was retained. To improve interpretation of the $\beta$ coefficients, the independent THI variable was centered before creating the squared term (Dalal and Zickar, 2012).

For time spent at the drinker, frequency of visits to the drinker, and number of competitive replacements at the drinker, the maximum THI averaged over $3 \mathrm{~d}$ generated lower AIC values than the average mean THI over $3 \mathrm{~d}$. For water intake, the AIC values for mean and maximum THI were similar, but the model with maximum THI had a higher coefficient of determination, so all analysis were based on maximum THI. The vertex of the parabola in the quadratic models (i.e., the maximum THI threshold at which dairy cow drinking behavior began to change) was determined by taking the first derivative of the quadratic function, resulting in the formula $\mathrm{x}=-\beta_{\mathrm{x}} / 2 \times \beta_{\mathrm{x}}{ }^{2}$.

Cow-Level Drinking Behavior. For the cow-level analysis ( $\mathrm{n}=69$ cows), 30 cows were excluded due to health disorders (metritis, retained placenta, mastitis, lameness, ketosis, milk fever; for a full description of disease diagnosis, see Lomb et al., 2018a) or missing health data. Two cows were involved in too few competitive interactions at the drinker $(\mathrm{n}<8$; Hohenbrink and Meinecke-Tillmann, 2012) to accurately calculate level of competitive success and were also excluded, leaving 37 cows in the analysis. Seven cows were classified as having high competitive success at the drinker, 25 were classified as having medium success, and 5 were classified as having low success.

Average daily measures of drinking behaviors for each cow (time spent at the drinker, frequency of visits to the drinker, water intake, number of competitive replacements as an actor or reactor) were calculated. The distributions of each drinking behavior per day were 
screened for the presence of outliers. Extreme outliers (i.e., more than 3 times outside the interquartile range) were deemed water bin malfunctions and removed from the data set. Differences in drinking behavior in relation to increasing THI between cows with different levels of competitive success at the drinker were analyzed using a mixed model, with day relative to calving specified as a repeated measure and a first-order autoregressive covariance structure. Fixed effects were level of competitive success at the drinker, daily milk yield, and 3-d maximum THI for the models with time spent at the drinker, time spent at the drinker per visit, and frequency of visits to the drinker as outcome measures.

Along with ambient temperature, feed intake has been shown to be predictive of water intake (see Cardot et al., 2008). Feed intake was explored as a potential explanatory variable for water intake, time spent at the drinker, and frequency of visits to the drinker. Feed intake was not highly correlated with time spent at the drinker $(\mathrm{r}=0.07)$ or frequency of visits to the drinker $(\mathrm{r}=0.08)$ but was correlated with water intake $(\mathrm{r}=$ 0.65 ); thus, we considered feed intake in our analysis of water intake in the cow-level models.

A multivariable linear mixed model was used to assess the effect of THI on water intake, controlling for level of competitive success at the drinker, feed intake, and milk yield. An ANOVA was performed to assess model fit, where the final model was compared with a model that was the same except that the variables THI and level of competitive success at the drinker were removed one by one, and both together. The final model that included both THI and social rank decreased the residual sum of squares compared with the models without one or both of these variables. The total variation in water intake accounted for by each explanatory variable was $19.2 \%$ for THI, $10.4 \%$ for milk yield, $39.9 \%$ for feed intake, and $12.2 \%$ for level of competitive success at the drinker (measured with the partial omega squared, which is the proportion of variance in the dependent variable accounted for by the independent variable, analogous to adjusted coefficient of determination, and adjusted for bias). Feed intake was thus included as a fixed effect for the model with water intake as the outcome measure.

Biologically plausible interactions with maximum THI were examined (level of competitive success at the drinker, daily milk yield, feed intake) and retained in the model when $P<0.05$. Plots of residuals were examined to ensure approximate normal distribution and determine whether transformations of the data were required. Studentized residuals greater than 3 or less than -3 were investigated as potential outliers (Dohoo et al., 2003). Outliers were deleted if they were the first or last day a cow was in the pen, as it was likely that the cow was not in the pen the whole day. Collinearity was not a problem in the models. To normalize residuals, a natural log-transformation was applied to time spent at the drinker and time spent at the drinker per visit, and a square root transformation was applied to frequency of visit to the drinker; water intake did not require transformation.

Exploratory Analysis on the Distribution of Drinking Behavior. The daily time distribution of each drinking behavior per cow was also examined based on level of competitive success at the drinker. Each 24-h time period was divided into six 4-h segments (0000-0400, 0400-0800, 0800-1200, 1200-1600, 1600-2000, and 2000-2400 h). The 4 -h bin size was chosen to improve interpretation of the time trends in drinking behavior, as the differences between the drinking behaviors of cows based on level of competitive success at the drinker were less clear with smaller bins. Analyses were separated into 2 categories based on whether the 3 - $\mathrm{d}$ maximum THI was above or below 72 to account for how the daily distribution of each drinking behavior was affected by high THI.

To identify times of peak competition at the drinker, the average number of competitive events that occurred during each 4 -h segment was calculated per day. Water intake, time spent at the drinker, and frequency of visits to the drinker, along with the proportion of each behavior performed in each 4 -h time segment out of the total daily expression of each behavior, were calculated per cow.

Table 1. Average and maximum daily values for air temperature, relative humidity (RH), and temperaturehumidity index (THI)

\begin{tabular}{|c|c|c|c|c|c|c|}
\hline \multirow[b]{2}{*}{ Variable } & \multicolumn{3}{|c|}{ 24-h mean } & \multicolumn{3}{|c|}{ 24-h maximum } \\
\hline & Mean & $\mathrm{SD}$ & Range & Mean & $\mathrm{SD}$ & Range \\
\hline Temperature $\left({ }^{\circ} \mathrm{C}\right)$ & 18.8 & 3.1 & $12.5-24.8$ & 24.2 & 4.8 & $13.4-32.6$ \\
\hline $\mathrm{RH}(\%)$ & 74.4 & 8.1 & $56.8-95.3$ & 95.3 & 3.6 & $77.0-99.0$ \\
\hline THI & 64.0 & 4.4 & $54.7-72.4$ & 70.9 & 5.9 & $56.3-81.3$ \\
\hline
\end{tabular}




\section{RESULTS}

Daily mean and maximum temperature, $\mathrm{RH}$, and THI over the entire trial period are summarized in Table 1 . The THI was $\geq 68$ on $45 \mathrm{~d}$ and $\geq 72$ on $28 \mathrm{~d}$ of the $59 \mathrm{~d}$ included in our analysis.

\section{Group-Level Drinking Behavior}

The average time spent at the drinker was $25.6 \pm$ $1.53 \mathrm{~min} / \mathrm{d}$ (range: $11.7-54.0 \mathrm{~min} / \mathrm{d}$ ), the average time spent at the drinker per visit was $81.0 \pm 2.35 \mathrm{~s} /$ visit (range: $54.6-115.3 \mathrm{~s} /$ visit), the average frequency of visits to the drinker was $19.0 \pm 0.6$ visits/d (range: 10-31 visits/d), the average water intake was $96.9 \pm$ $1.06 \mathrm{~kg} / \mathrm{d}$ (range: $77.3-112.7 \mathrm{~kg} / \mathrm{d}$ ), and the average number of competitive replacements was $54.0 \pm 4.5$ replacements/d (range: 12-172 replacements/d).

As maximum THI increased, cows spent more time at the drinker (adjusted $\mathrm{R}^{2}=0.77, \mathrm{df}=56$, intercept $=21.52 \pm 1.01, \beta_{\text {linear }}=1.92 \pm 0.14, P_{\text {linear }}<0.0001$, $\beta_{\text {quadratic }}=0.16 \pm 0.03, P_{\text {quadratic }}<0.0001 ;$ Figure 1a), visited the drinker more often (adjusted $\mathrm{R}^{2}=0.76$, $\mathrm{df}=56$, intercept $=17.42 \pm 0.38, \beta_{\text {linear }}=0.73 \pm$ $0.05, P_{\text {linear }}<0.0001, \beta_{\text {quadratic }}=0.05 \pm 0.01, P_{\text {quadratic }}<$ 0.0001 ; Figure $1 \mathrm{~b})$, drank more water $\left(\mathrm{R}^{2}=0.20, \mathrm{df}=\right.$ 57 , intercept $=96.02 \pm 1.32, \beta_{\text {linear }}=0.72 \pm 0.19, P_{\text {linear }}$ $=0.0004$; Figure 1c), and engaged in a greater number of competitive replacements at the drinker (adjusted $\mathrm{R}^{2}$ $=0.75, \mathrm{df}=56$, intercept $=41.41 \pm 3.06, \beta_{\text {linear }}=5.52$ $\pm 0.44, P_{\text {linear }}<0.0001, \beta_{\text {quadratic }}=0.48 \pm 0.08, P_{\text {quadratic }}$ $<0.0001$; Figure 2). Time spent at the drinker per visit also increased along with maximum THI (adjusted $\mathrm{R}^{2}$ $=0.53, \mathrm{df}=56$, intercept $=76.50 \pm 2.25, \beta_{\text {linear }}=2.49$ $\pm 0.32, P_{\text {linear }}<0.0001, \beta_{\text {quadratic }}=0.17 \pm 0.06, P_{\text {quadratic }}$ $=0.005)$. For the quadratic models, time spent at the drinker and the number of competitive replacements at the drinker began to increase at a THI of 65 ; frequency of visits to the drinker began to increase at a THI of 64 .

\section{Cow-Level Drinking Behavior}

Cows with higher levels of competitive success at the drinker drank more water $\left(F_{2,34}=13.60, P<0.0001\right)$, cows with greater feed intake drank more water $\left(F_{1,539}\right.$ $=425.18, P<0.0001)$, and cows with greater milk yield drank more water $\left(F_{1,539}=16.83, P=0.0001\right)$. There was a positive interaction between milk yield and THI for frequency of visits to the drinker, where cows with greater milk yield made more visits to the drinker as THI increased $\left(F_{1,539}=28.51, P<0.0001\right)$, but level of competitive success did not affect frequency of visits to the drinker $\left(F_{2,34}=2.75, P=0.08\right)$. There was a positive interaction between milk yield and THI for time spent at the drinker, where cows with greater milk yield spent more time at the drinker as THI increased $\left(F_{1,539}=15.90, P<0.0001\right)$, but level of competitive success at the drinker did not affect time spent at the drinker $\left(F_{2,34}=1.29, P=0.29\right)$. Cows with greater milk yield had longer visits to the drinker $\left(F_{1,540}=23.68\right.$, $P<0.0001)$, but level of competitive success did not affect time spent at the drinker per visit $\left(F_{2,34}=0.86\right.$, $P=0.43)$. The interaction between level of competitive success at the drinker and THI was not significant for water intake, frequency of visits to the drinker, time spent at the drinker, or time spent at the drinker per visit.

\section{Exploratory Analysis of the Distribution of Drinking Behavior}

Peak times of competition at the drinker were between 0800 and $1200 \mathrm{~h}$ and between 1600 and 2000 $\mathrm{h}$ (Figure 3). On days where the THI was $<72$, the average number of replacements that occurred at each peak was roughly similar $(0800-1200 \mathrm{~h}=4.5$ replacements $/ 4 \mathrm{~h} ; 1600-2000 \mathrm{~h}=7.2$ replacements $/ 4 \mathrm{~h})$, but on days where the THI was $\geq 72$, the average number of replacements appeared to be higher in the afternoon $(0800-1200 \mathrm{~h}=11.7 \pm 1.3$ replacements $/ 4 \mathrm{~h} ; 1600-2000$ $\mathrm{h}=19.8 \pm 2.2$ replacements $/ 4 \mathrm{~h}$; no inferential tests were performed for the exploratory analysis).

The distribution of water intake for cows of low and high competitive success at the drinker is depicted in Figure 4. On days where the maximum THI was $<72$, regardless of level of competitive success at the drinker, all cows had peaks in the proportion of water intake between 0800 and $1200 \mathrm{~h}$ (high success: $22.1 \pm 1.1 \%$; medium success: $26.6 \pm 1.0 \%$; low success: $26.0 \pm 1.4 \%$ of total daily water intake) and between 1600 and 2000 h (high success: $26.6 \pm 1.0 \%$; medium success: 27.5 $\pm 0.6 \%$; low success: $27.2 \pm 1.1 \%$ of total daily water intake). When the maximum THI was $\geq 72$, both highand medium-success cows maintained peaks of water intake between 0800 and $1200 \mathrm{~h}$ (high success: $21.1 \pm$ $1.2 \%$; medium success: $26.0 \pm 0.6 \%$ of total daily water intake) and between 1600 and $2000 \mathrm{~h}$ (high success: $22.3 \pm 1.1 \%$; medium success: $22.8 \pm 0.6 \%$ of total daily water intake). Low-success cows maintained one peak of water intake between 0800 and $1200 \mathrm{~h}(24.4 \pm$ $2.0 \%$ of total daily water intake), but the second peak shifted to 2000 to $2400 \mathrm{~h}(23.7 \pm 1.9 \%$ of total daily water intake).

On days where the maximum THI was $<72$, the distribution of time spent at the drinker and frequency of visits to the drinker were not affected by level of competitive success at the drinker. All cows had peaks in the proportion of time spent at the drinker between 

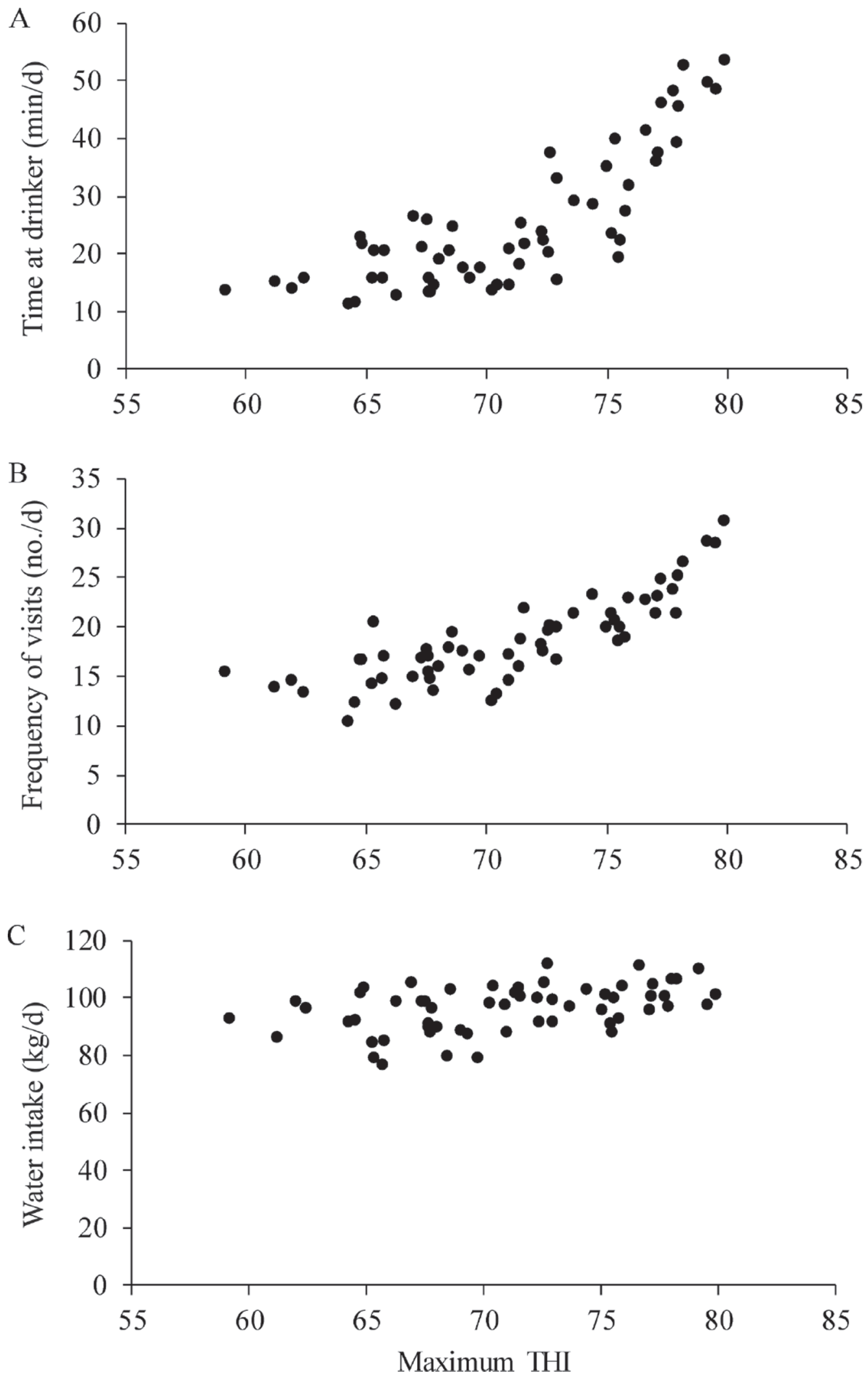

Figure 1. The average (A) time spent at the drinker ( $\mathrm{min} / \mathrm{d}),(\mathrm{B})$ frequency of visits to the drinker (no./d), and $(\mathrm{C})$ water intake $(\mathrm{kg} / \mathrm{d}) \mathrm{per}$ cow in relation to the maximum temperature-humidity index (THI) averaged over the day of observation and the 2 previous days. Each point shows the average drinking behavior over all 20 cows in the group for each day of observation. 


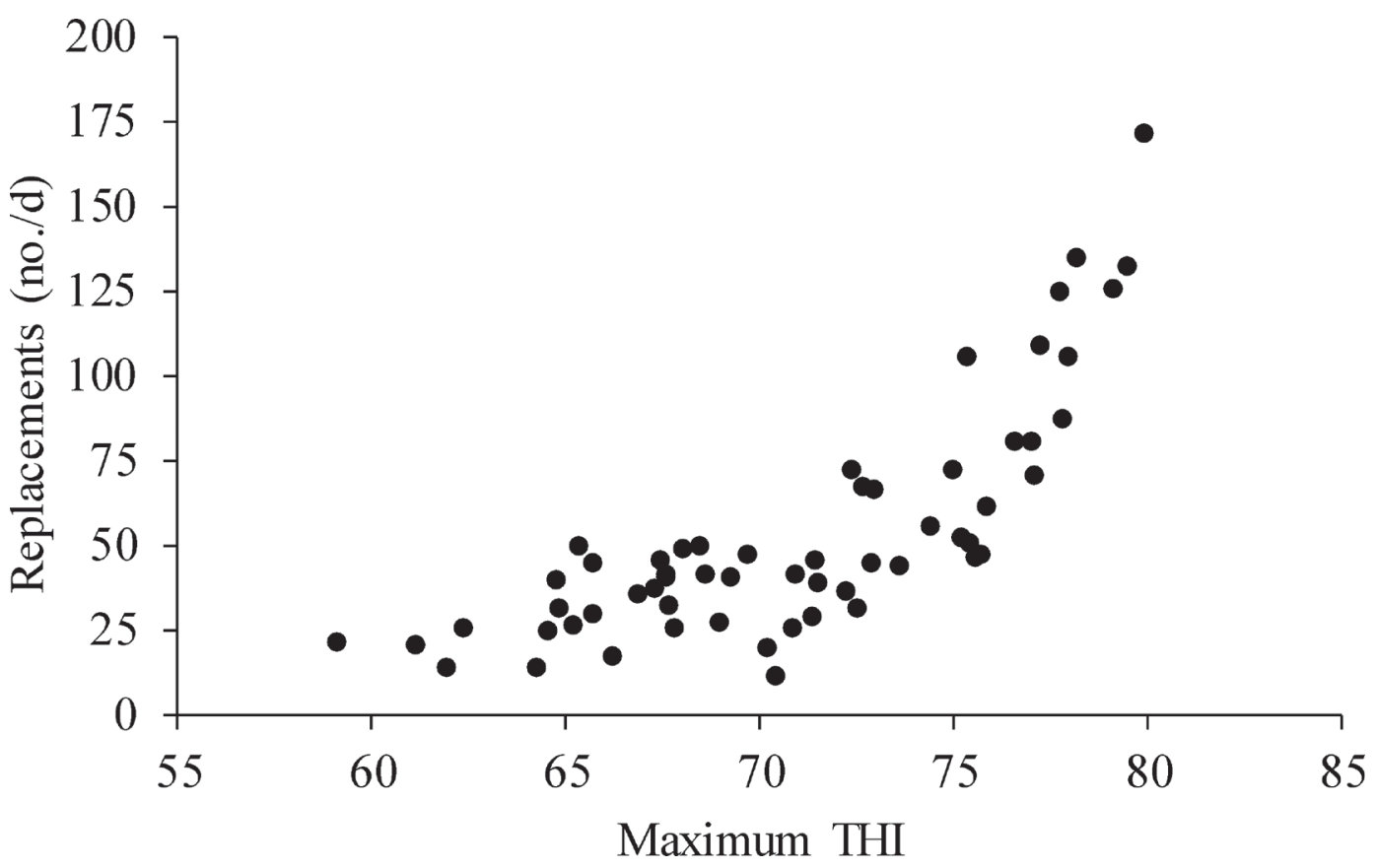

Figure 2. The total number of competitive replacements at the drinker (no./d) in relation to the maximum temperature-humidity index (THI) averaged over the day of observation and the 2 previous days. Each point shows the sum of replacements over all 20 cows in the group for each day of observation.

0800 and $1200 \mathrm{~h}$ (high success: $20.6 \pm 0.9 \%$; medium success: $22.9 \pm 0.7 \%$; low success: $24.1 \pm 1.2 \%$ of total time spent at the drinker) and between 1600 and 2000 h (high success: $24.3 \pm 1.0 \%$; medium success: $23.4 \pm$ 0.7\%; low success: $23.5 \pm 1.3 \%$ of total time spent at the drinker) as well as peaks in the frequency of visits to the drinker between 0800 and $1200 \mathrm{~h}$ (high success: $19.8 \pm 1.3 \%$; medium success: $22.5 \pm 0.7 \%$; low success: $26.7 \pm 1.4 \%$ of total daily frequency of visits to the drinker) and between 1600 and $2000 \mathrm{~h}$ (high success: $28.6 \pm 1.4 \%$; medium success: $25.9 \pm 0.7 \%$; low success: $26.3 \pm 1.6 \%$ of total daily frequency of visits to the drinker).

When the maximum THI was $\geq 72$, high- and medium-success cows maintained peak time spent at the drinker between 1600 and $2000 \mathrm{~h}$ (high success: $24.3 \pm$ $1.4 \%$; medium success: $25.3 \pm 0.7 \%$ of total daily time spent at the drinker), whereas low-success cows had an earlier peak between 1200 and $1600 \mathrm{~h}(26.5 \pm 2.4 \%$ of total daily time spent at the drinker). High- and medium-success cows also maintained peak frequency of visits to the drinker between 0800 and $1200 \mathrm{~h}$ (high success: $19.0 \pm 1.6 \%$; medium success: $22.5 \pm 0.7 \%$ of total daily frequency of visits to the drinker) and 1600 to 2000 h (high success: $27.2 \pm 1.8 \%$; medium success: $25.5 \pm 0.8 \%$ of total daily frequency of visits to the drinker). Low-success cows maintained only one peak in frequency of visits to the drinker at 0800 to $1200 \mathrm{~h}$
$(22.6 \pm 1.7 \%$ of total daily frequency of visits to the drinker).

\section{DISCUSSION}

This is the first study to examine how THI relates to behavior at the drinker for indoor, loose-housed dairy cattle. As THI increased, dairy cows spent more time at the drinker, visited the drinker more often, increased water intake, and engaged in more competitive behavior at the drinker. In addition to contributing to the literature that shows that dairy cows increase their drinking behavior (Ammer et al., 2018) and become more aggressive (Pilatti et al., 2019) when hot, the results of this study suggest that socially subordinate cows may be more vulnerable to increasing THI, as they shifted their drinking behavior to different times of the day.

Temperature is well known to be associated with water intake in dairy cows (Murphy et al., 1983; Meyer et al., 2004; Cardot et al., 2008). Other studies have found that drinking time (Cook et al., 2007), frequency (Ammer et al., 2018), and intake (McDowell et al., 1969; Beatty et al., 2006; Ammer et al., 2018) increase with increasing THI and ambient temperature. Body water is lost as a result of panting and sweating (Kadzere et al., 2002), and ingestion of water increases heat loss and combats dehydration (Vizzotto et al., 2015). Compared with time spent at the drinker and frequency of visits, 
the current study found less effect of increasing THI on water intake. Apart from actually consuming water, dairy cows may also be attracted to the cooling effect of water on their skin and in the area around the drinker (Palacio et al., 2015), as passing air over water leads to evaporative cooling (West, 2003). Increased time spent at a resource without greater intake may also suggest that cows are attempting to defend a resource that they are motivated to obtain (Val-Laillet et al., 2008).

The quadratic relationship between THI and time at the drinker, frequency of visits to the drinker, and competition at the drinker indicates that changes in behavior become more pronounced when the maximum THI over a 3-d period exceeds approximately 65. Similarly, Brown-Brandl et al. (2005) noticed a quadratic relationship between ambient temperature and feed intake in cattle, identifying a threshold of $18.5^{\circ} \mathrm{C}$ (roughly corresponding to a THI of 64 in the current data set). However, these authors noted that there may be insufficient data to accurately identify this breakpoint, and this may also be an issue in the current study. Our values, and that of Brown-Brandl et al. (2005), are lower than the THI of 68 (Zimbelman et al., 2009) or 72 (Armstrong, 1994) that are more commonly associated with heat stress, suggesting that dairy cows may be more vulnerable to heat stress than previously thought. Interestingly, unlike the other drinking behaviors studied, the relationship between
THI and water intake remained linear, suggesting that time spent at the drinker, frequency of visits to the drinker, and competition at the drinker may be more useful to signify the onset of heat stress.

Despite our hypothesis that level of competitive success at the drinker would affect the rate of change in drinking behaviors during high THI, the interaction of level of competitive success at the drinker with THI was not significantly related to water intake, frequency of visits to the drinker, and time spent at the drinker. This result suggests that the increase in these drinking behaviors due to increasing THI does not depend on the level of competitive success of the cow. However, our exploratory analysis revealed that increasing THI did shift how cows with low competitive success at the drinker distributed their drinking behavior throughout the day. On days where THI was $<72$, cows of all levels of competitive success at the drinker had similar patterns of drinking behavior. However, when the THI was $\geq 72$, the distribution of drinking behavior for high- and medium-success cows remained relatively unchanged, but low-success cows had a lower proportion of drinking behavior from 1600 to $2000 \mathrm{~h}$. During the 1600 to $2000 \mathrm{~h}$ time segment the daily THI reached its maximum and competition at the drinker was greatest. Thus, cows with low competitive success at the drinker appeared to shift their drinking behavior to avoid peak times of day. We caution readers that our results are

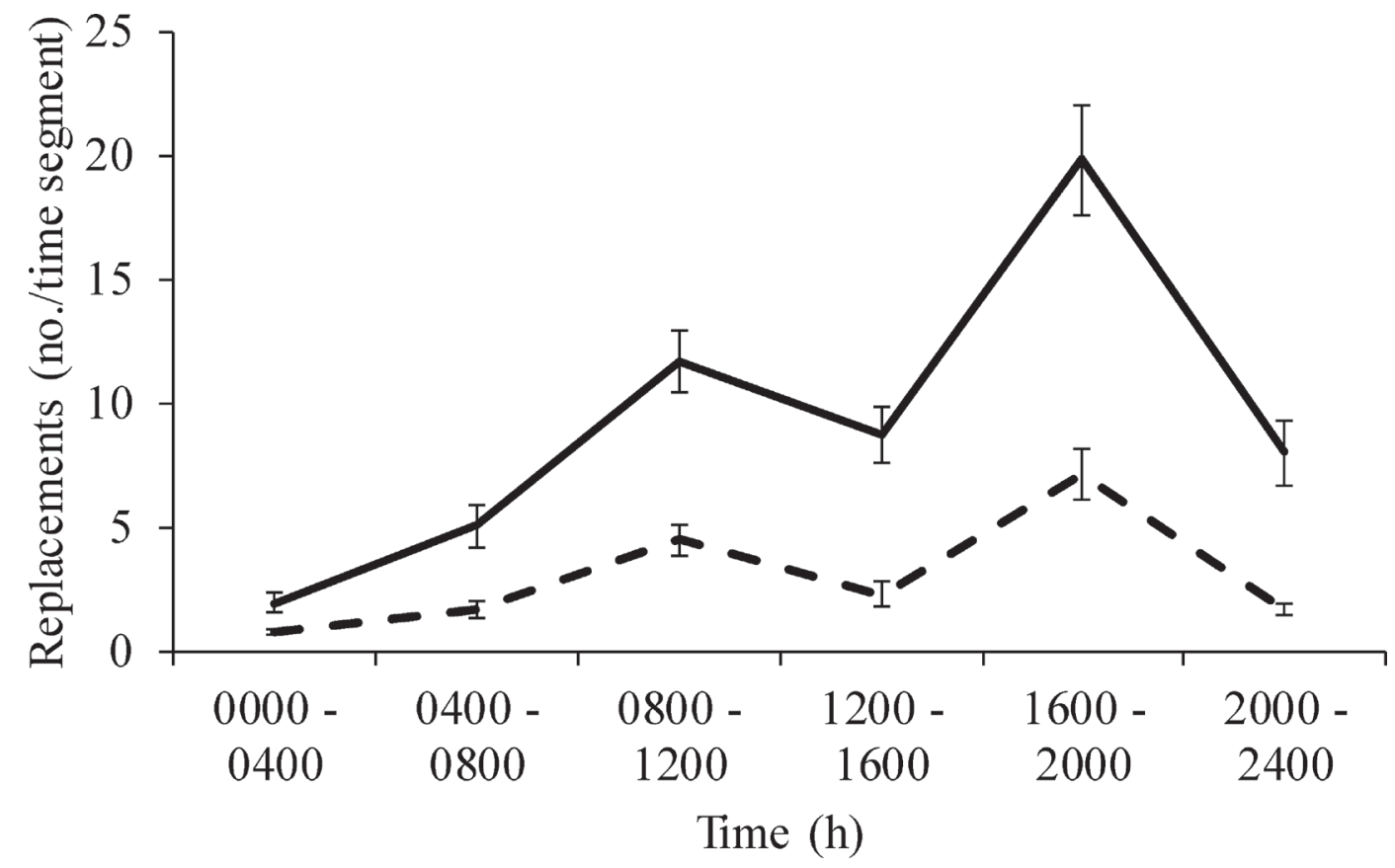

Figure 3. Number of replacements at the drinker (mean $\pm \mathrm{SE}$ ) that occurred per day during each 4-h segment when the temperature-humidity index was $\geq 72$ (solid line) versus $<72$ (dashed line). 

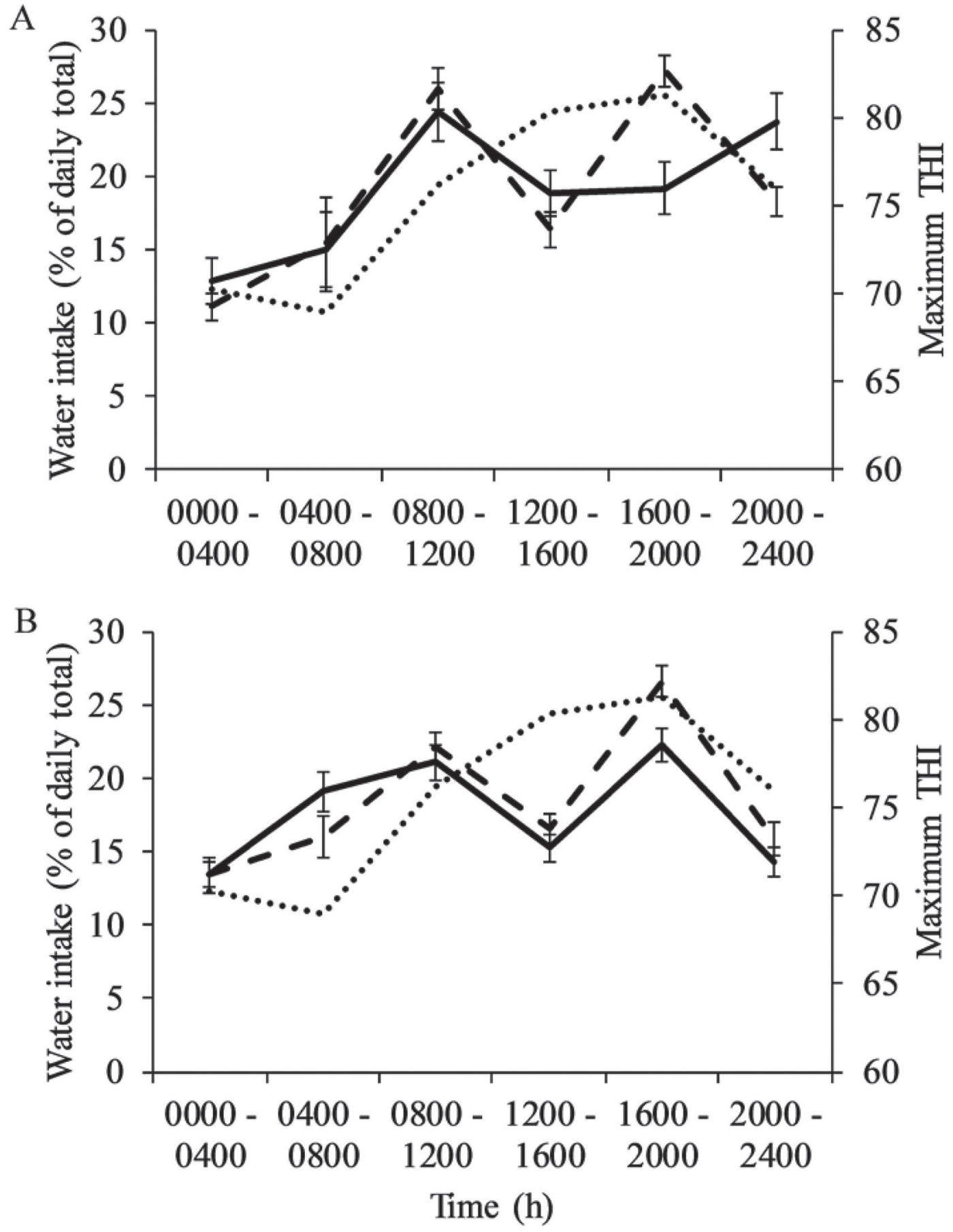

Figure 4. The distribution of water intake (measured as the proportion of total daily intake that occurred during each 4-h segment) when the temperature-humidity index (THI) was $>72$ (solid line) or $<72$ (dashed line) for cows with (A) low competitive success at the drinker and (B) high competitive success at the drinker. Values represent the mean $\pm \mathrm{SE}$ of all cows at each level of competitive success. Maximum THI during each time segment is represented with a dotted line.

limited by a low sample size of cows at each level of competitive success at the drinker; future work should expand on these findings with more cows.

Increased competition at the drinker may negatively affect the ability of subordinate cows to deal with heat stress. Similar to the results of the current study, Olofsson (1999) observed that during competition at the feed bunk, cows of lower social rank adjusted their behavior to a greater extent than did dominant cows, for example, by altering their feeding times to avoid feeding 
at busy times of the day. The negative implication of this shift in feeding behavior is the risk of consuming feed of less nutritional value due to sorting (DeVries et al., 2004). If subordinate cows need to redistribute their drinking behavior to avoid peak times of day, this could reduce their ability to cope during high temperatures; water ingestion is an effective way for cows to reduce their body temperature (Coimbra et al., 2012).

The implications of competition at the drinker and a shift in drinking behavior away from the hottest part of the day have yet to be determined. It can be postulated that the inability to drink at a preferred time may lead to feelings of frustration; as Polsky and von Keyserlingk (2017) suggested, frustration could be caused by the inability to perform thermoregulatory behavior during heat stress. Competition is also a source of physiological stress and can lead to increased activity and heart rate (Hetti Arachchige et al., 2014), perhaps contributing to heat load for cows that compete for access to the drinker. Additionally, the timing of water intake is related to the timing of feed intake. Ominski et al. (2002) found that heat-stressed cows fed in the morning consumed a greater proportion of their daily water intake during the day, and evening-fed cows consumed a greater proportion during the night. A shift in drinking behavior could be related to the negative consequence of a shift in feeding behavior discussed above.

Inclusion of feed intake in our analysis of drinking behavior at the cow level allowed us to rule out the possibility that increased drinking behavior was solely in response to changes in feeding behavior. Time spent at the drinker and frequency of visits to the drinker were not related to feed intake but rather increased in response to THI. Although water intake was associated with feed intake, we found that water intake increased along with increasing THI, even after controlling for feed intake.

High THI is used to infer when dairy cows may be experiencing heat stress; however, using environmental factors alone assumes that all cows are affected equally. There is likely individual variation in the THI threshold when dairy cows become heat stressed (Sánchez et al., 2009). Individual characteristics, such as level of milk production (Ravagnolo and Misztal, 2000), breed (Pereira et al., 2014), coat length (Dikmen et al., 2008), and size (Busby and Loy, 1996), can affect a cow's heat tolerance. In the current study, individual milk yield affected drinking behavior, where greater milk yield was associated with increased water intake, and time spent at the drinker and frequency of visits to the drinker increased especially in response to increasing THI, suggesting that high-producing dairy cows are more susceptible to elevated ambient temperatures (see Kadzere et al., 2002). Using individual measures, such as behavior at the drinker, could allow for individualized management.

Several management strategies are available to mitigate heat stress (Collier et al., 2006), but cows often have little individual control over access to cooling options. Heat abatement strategies that allow individual choice may be beneficial, and the results of the current study suggest that simply providing cows better access to water provides one such opportunity for cow agency.

There are limitations to the current study. The THI data were obtained from the local weather station and not from inside the barn. This may have underestimated THI, which is typically higher inside a barn (Shock et al., 2016). Different microclimates can also exist within a barn (Collier et al., 2006). Schüller and Heuwieser (2016) found that the average THI at cow-level loggers was 2.3 points higher than at other loggers placed elsewhere in the barn. Additionally, the Insentec water bins are different from typical water troughs on commercial dairy farms, and trough design affects drinking behavior (Pinheiro Machado Filho et al., 2004). Last, data were collected as part of a larger study (Neave et al., 2017, 2018; Lomb et al., 2018a,b); the dynamic group composition required for that study may have increased competition (see von Keyserlingk et al., 2008). In the current study, group composition was changed slowly (approximately 2 to 4 cows were moved every few days); it is unknown how much of an effect this has on competitive behavior. Regrouping frequently happens in commercial herds, thus making the results of the current study applicable to on-farm situations. The current study was observational; future work should consider experimentally varying heat load to allow stronger causal inferences about the effects of heat stress on drinking behavior. In addition, measures of individual body temperature would allow for a more sensitive analysis, taking into account that different cows may be more affected by heat stress.

\section{CONCLUSIONS}

With increasing THI, cows spent more time at the drinker, had a greater frequency of drinker visits, drank more water, and engaged in more competition at the drinker. Cows with low competitive success at the drinker shifted their drinking behavior on hot days to avoid the drinker during times of high competition. These behaviors may be useful biomarkers of heat stress, especially for farms where attendance at the drinker can be monitored electronically. 


\section{ACKNOWLEDGMENTS}

We thank Julia Lomb [University of British Columbia (UBC), Vancouver, BC, Canada], Julie Huzzey (California Polytechnic State University, San Luis Obispo), and the staff and students at the UBC Dairy Education and Research Center (Agassiz, BC, Canada) for help in collecting the data used for this analysis. We also thank Hanna Eriksson (UBC) and Ruan Daros (UBC) for their help in the initial stages of conceptualizing this analysis. This research was supported by Canada's Natural Sciences and Engineering Research Council (NSERC) Industrial Research Chair Program with industry contributions from the Dairy Farmers of Canada (Ottawa, ON, Canada), British Columbia Dairy Association (Burnaby, BC Canada), Westgen Endowment Fund (Milner, BC, Canada), Intervet Canada Corporation (Kirkland, QC, Canada), Novus International Inc. (Oakville, ON, Canada), Zoetis (Kirkland, QC, Canada), BC Cattle Industry Development Fund (Kamloops, BC, Canada), Alberta Milk (Edmonton, AB, Canada), Valacta (St. Anne-de-Bellevue, QC, Canada), and CanWest DHI (Guelph, ON, Canada). The authors have not stated any conflicts of interest.

\section{REFERENCES}

Allen, J. D., L. W. Hall, R. J. Collier, and J. F. Smith. 2015. Effect of core body temperature, time of day, and climate conditions on behavioral patterns of lactating dairy cows experiencing mild to moderate heat stress. J. Dairy Sci. 98:118-127. https://doi.org/10 .3168/jds.2013-7704.

Ammer, S., C. Lambertz, D. von Soosten, K. Zimmer, U. Meyer, S. Dänicke, and M. Gauly. 2018. Impact of diet composition and temperature-humidity index on water and dry matter intake of high-yielding dairy cows. J. Anim. Physiol. Anim. Nutr. (Berl.) 102:103-113. https://doi.org/10.1111/jpn.12664.

Armstrong, D. V. 1994. Heat stress interaction with shade and cooling. J. Dairy Sci. 77:2044-2050. https://doi.org/10.3168/jds.S0022 -0302(94)77149-6.

Beatty, D. T., A. Barnes, E. Taylor, D. Pethick, M. McCarthy, and S. K. Maloney. 2006. Physiological responses of Bos taurus and Bos indicus cattle to prolonged, continuous heat and humidity. J. Anim. Sci. 84:972-985. https://doi.org/10.2527/2006.844972x.

Bernabucci, U., S. Biffani, L. Buggiotti, A. Vitali, N. Lacetera, and A. Nardone. 2014. The effects of heat stress in Italian Holstein dairy cattle. J. Dairy Sci. 97:471-486. https://doi.org/10.3168/jds.2013 $-6611$.

Bernabucci, U., N. Lacetera, L. H. Baumgard, R. P. Rhoads, B. Ronchi, and A. Nardone. 2010. Metabolic and hormonal acclimation to heat stress in domesticated ruminants. Animal 4:1167-1183. https: //doi.org/10.1017/S175173111000090X.

Biffani, S., U. Bernabucci, A. Vitali, N. Lacetera, and A. Nardone. 2016. Short communication: Effect of heat stress on nonreturn rate of Italian Holstein cows. J. Dairy Sci. 99:5837-5843. https://doi .org/10.3168/jds.2015-10491.

Bouraoui, R., M. Lahmar, A. Majdoub, M. Djemali, and R. Belyea. 2002. The relationship of temperature-humidity index with milk production of dairy cows in a Mediterranean climate. Anim. Res. 51:479-491. https://doi.org/10.1051/animres:2002036.

Brown-Brandl, T. M., R. A. Eigenberg, G. L. Hahn, J. A. Nienaber, T. L. Mader, D. E. Spiers, and A. M. Parkhurst. 2005. Analyses of thermoregulatory responses of feeder cattle exposed to simulated heat waves. Int. J. Biometeorol. 49:285-296. https://doi.org/10 .1007/s00484-004-0250-2.

Burnham, K. P., and D. R. Anderson. 2001. Kullback-Leibler information as a basis for strong inference in ecological studies. Wildl. Res. 28:111-119. https://doi.org/10.1071/WR99107.

Busby, D., and D. Loy. 1996. Heat stress in feedlot cattle: Producer survey results. Beef Research Report, AS Leaflet R1348. Iowa State University, Ames, IA.

Cardot, V., Y. Le Roux, and S. Jurjanz. 2008. Drinking behavior of lactating dairy cows and prediction of their water intake. J. Dairy Sci. 91:2257-2264. https://doi.org/10.3168/jds.2007-0204.

Chapinal, N., D. M. Veira, D. M. Weary, and M. A. G. von Keyserlingk. 2007. Technical note: Validation of a system for monitoring individual feeding and drinking behavior and intake in group-housed cattle. J. Dairy Sci. 90:5732-5736. https://doi.org/ $10.3168 /$ jds.2007-0331.

Coimbra, P. A. D., L. C. P. Machado Filho, and M. J. Hötzel. 2012. Effects of social dominance, water trough location and shade availability on drinking behaviour of cows on pasture. Appl. Anim. Behav. Sci. 139:175-182. https://doi.org/10.1016/j.applanim.2012 .04.009.

Collier, R. J., G. E. Dahl, and M. J. VanBaale. 2006. Major advances associated with environmental effects on dairy cattle. J. Dairy Sci. 89:1244-1253. https://doi.org/10.3168/jds.S0022-0302(06)72193 -2 .

Cook, N. B., R. L. Mentink, T. B. Bennett, and K. Burgi. 2007. The effect of heat stress and lameness on time budgets of lactating dairy cows. J. Dairy Sci. 90:1674-1682. https://doi.org/10.3168/ jds.2006-634.

Dalal, D. K., and M. J. Zickar. 2012. Some common myths about centering predictor variables in moderated multiple regression and polynomial regression. Organ. Res. Methods 15:339-362. https:// doi.org/10.1177/1094428111430540.

Dash, S., A. K. Chakravarty, A. Singh, A. Upadhyay, M. Singh, and S. Yousuf. 2016. Effect of heat stress on reproductive performances of dairy cattle and buffaloes: A review. Vet. World 9:235-244. https: //doi.org/10.14202/vetworld.2016.235-244.

DeVries, T. J., M. A. G. von Keyserlingk, and D. M. Weary. 2004 Effect of feeding space on the inter-cow distance, aggression, and feeding behavior of free-stall housed lactating dairy cows. J. Dairy Sci. 87:1432-1438. https://doi.org/10.3168/jds.S0022 -0302(04)73293-2.

Dikmen, S., E. Alava, E. Pontes, J. M. Fear, B. Y. Dikmen, T. A. Olson, and P. J. Hansen. 2008. Differences in thermoregulatory ability between slick-haired and wild-type lactating Holstein cows in response to acute heat stress. J. Dairy Sci. 91:3395-3402. https: //doi.org/10.3168/jds.2008-1072.

Dohoo, I., M. Wayne, and H. Stryhn. 2003. Veterinary Epidemiology Research. AVC Inc., Charlottetown, PEI, Canada.

Galindo, F., and D. M. Broom. 2000. The relationships between social behaviour of dairy cows and the occurrence of lameness in three herds. Res. Vet. Sci. 69:75-79. https://doi.org/10.1053/rvsc.2000 .0391 .

Hetti Arachchige, A. D., A. D. Fisher, W. J. Wales, M. J. Auldist, M. C. Hannah, and E. C. Jongman. 2014. Space allowance and barriers influence cow competition for mixed rations fed on a feed-pad between bouts of grazing. J. Dairy Sci. 97:3578-3588. https://doi .org/10.3168/jds.2013-7553.

Hill, D. L., and E. Wall. 2017. Weather influences feed intake and feed efficiency in a temperate climate. J. Dairy Sci. 100:2240-2257. https://doi.org/10.3168/jds.2016-11047.

Hohenbrink, S., and S. Meinecke-Tillmann. 2012. Influence of social dominance on the secondary sex ratio and factors affecting hierarchy in Holstein dairy cows. J. Dairy Sci. 95:5694-5701. https://doi .org/10.3168/jds.2011-5281.

Kadzere, C. T., M. R. Murphy, N. Silanikove, and E. Maltz. 2002. Heat stress in lactating dairy cows: A review. Livest. Prod. Sci. 77:59-91. https://doi.org/10.1016/S0301-6226(01)00330-X.

Lomb, J., H. W. Neave, D. M. Weary, S. J. LeBlanc, J. M. Huzzey, and M. A. G. von Keyserlingk. 2018a. Changes in feeding, social, and lying behaviors in dairy cows with metritis following treatment 
with a nonsteroidal anti-inflammatory drug as adjunctive treatment to an antimicrobial. J. Dairy Sci. 101:4400-4411. https://doi .org/10.3168/jds.2017-13812.

Lomb, J., D. M. Weary, K. E. Mills, and M. A. G. von Keyserlingk. 2018b. Effects of metritis on stall use and social behavior at the lying stall. J. Dairy Sci. 101:7471-7479. https://doi.org/10.3168/ jds.2017-14149.

McDonald, P. V., M. A. G. von Keyserlingk, and D. M. Weary. 2019. Technical note: Using an electronic drinker to monitor competition in dairy cows. J. Dairy Sci. 102:3495-3500. https://doi.org/10 $.3168 /$ jds.2018-15585.

McDowell, R. E., E. G. Moody, P. J. Van Soest, R. P. Lehmann, and G. L. Ford. 1969. Effect of heat stress on energy and water utilization of lactating cows. J. Dairy Sci. 52:188-194. https://doi.org/10 .3168/jds.S0022-0302(69)86528-8.

Meyer, U., M. Everinghoff, D. Gädeken, and G. Flachowsky. 2004. Investigations on the water intake of lactating dairy cows. Livest. Prod. Sci. 90:117-121. https://doi.org/10.1016/j.livprodsci.2004 .03 .005 .

Murphy, M. R., C. L. Davis, and G. C. McCoy. 1983. Factors affecting water consumption by Holstein cows in early lactation. J. Dairy Sci. 66:35-38. https://doi.org/10.3168/jds.S0022-0302(83)81750-0.

Neave, H. W., J. Lomb, M. A. G. von Keyserlingk, A. Behnam-Shabahang, and D. M. Weary. 2017. Parity differences in the behavior of transition dairy cows. J. Dairy Sci. 100:548-561. https://doi.org/ 10.3168/jds.2016-10987.

Neave, H. W., J. Lomb, D. M. Weary, S. J. LeBlanc, J. M. Huzzey, and M. A. G. von Keyserlingk. 2018. Behavioral changes before metritis diagnosis in dairy cows. J. Dairy Sci. 101:4388-4399. https:// doi.org/10.3168/jds.2017-13078.

NRC. 1971. A Guide to Environmental Research on Animals. Natl. Acad. Sci., Washington, DC.

NRC. 2001. Nutrient Requirements of Dairy Cattle. 7th rev. ed. Natl. Acad. Sci., Washington, DC.

O'Connell, J., P. S. Giller, and W. Meaney. 1989. A comparison of dairy cattle behavioural patterns at pasture and during confinement. Isr. J. Agric. Res. 28:65-72.

Olofsson, J. 1999. Competition for total mixed diets fed for ad libitum intake using one or four cows per feeding station. J. Dairy Sci. 82:69-79. https://doi.org/10.3168/jds.S0022-0302(99)75210-0.

Ominski, K. H., A. D. Kennedy, K. M. Wittenberg, and S. A. Moshtaghi Nia. 2002. Physiological and production responses to feeding schedule in lactating dairy cows exposed to short-term, moderate heat stress. J. Dairy Sci. 85:730-737. https://doi.org/10 .3168/jds.S0022-0302(02)74130-1.

Palacio, S., R. Bergeron, S. Lachance, and E. Vasseur. 2015. The effects of providing portable shade at pasture on dairy cow behavior and physiology. J. Dairy Sci. 98:6085-6093. https://doi.org/10 $.3168 /$ jds.2014-8932.

Pereira, A. M. F., E. L. Titto, P. Infante, C. G. Titto, A. M. Geraldo, A. Alves, T. M. Leme, F. Baccari Jr., and J. A. Almeida. 2014 Evaporative heat loss in Bos taurus: Do different cattle breeds cope with heat stress in the same way? J. Therm. Biol. 45:87-95. https://doi.org/10.1016/j.jtherbio.2014.08.004

Pilatti, J. A., F. M. C. Vieira, F. Rankrape, and E. S. Vismara. 2019. Diurnal behaviors and herd characteristics of dairy cows housed in a compost-bedded pack barn system under hot and humid conditions. Animal 13:399-406. https://doi.org/10.1017/ S1751731118001088.

Pinheiro Machado Filho, L. C., D. L. Teixeira, D. M. Weary, M. A. G. von Keyserlingk, and M. J. Hötzel. 2004. Designing better water troughs: Dairy cows prefer and drink more from larger troughs.
Appl. Anim. Behav. Sci. 89:185-193. https://doi.org/10.1016/j .applanim.2004.07.002.

Polsky, L., and M. A. G. von Keyserlingk. 2017. Invited review: Effects of heat stress on dairy cattle welfare. J. Dairy Sci. 100:8645-8657. https://doi.org/10.3168/jds.2017-12651

Proudfoot, K. L., D. M. Veira, D. M. Weary, and M. A. G. von Keyserlingk. 2009. Competition at the feed bunk changes the feeding, standing, and social behavior of transition dairy cows. J. Dairy Sci. 92:3116-3123. https://doi.org/10.3168/jds.2008-1718.

Ravagnolo, O., and I. Misztal. 2000. Genetic component of heat stress in dairy cattle, parameter estimation. J. Dairy Sci. 83:2126-2130. https://doi.org/10.3168/jds.S0022-0302(00)75095-8.

Sánchez, J. P., I. Misztal, I. Aguilar, B. Zumbach, and R. Rekaya. 2009. Genetic determination of the onset of heat stress on daily milk production in the US Holstein cattle. J. Dairy Sci. 92:40354045. https://doi.org/10.3168/jds.2008-1626.

Schüller, L. K., and W. Heuwieser. 2016. Measurement of heat stress conditions at cow level and comparison to climate conditions at stationary locations inside a dairy barn. J. Dairy Res. 83:305-311. https://doi.org/10.1017/S0022029916000388.

Schütz, K. E., A. R. Rogers, Y. A. Poulouin, N. R. Cox, and C. B. Tucker. 2010. The amount of shade influences the behavior and physiology of dairy cattle. J. Dairy Sci. 93:125-133. https://doi .org/10.3168/jds.2009-2416.

Shock, D. A., S. J. LeBlanc, K. E. Leslie, K. Hand, M. A. Godkin, J. B. Coe, and D. F. Kelton. 2016. Studying the relationship between on-farm environmental conditions and local meteorological station data during the summer. J. Dairy Sci. 99:2169-2179. https://doi .org $/ 10.3168 /$ jds.2015-9795.

Val-Laillet, D., D. M. Veira, and M. A. G. von Keyserlingk. 2008. Short communication: Dominance in free-stall-housed dairy cattle is dependent upon resource. J. Dairy Sci. 91:3922-3926. https:// doi.org/10.3168/jds.2008-1332.

Vizzotto, E. F., V. Fischer, A. Thaler Neto, A. S. Abreu, M. T. Stumpf, D. Werncke, F. A. Schmidt, and C. M. McManus. 2015. Access to shade changes behavioral and physiological attributes of dairy cows during the hot season in the subtropics. Animal 9:1559-1566. https://doi.org/10.1017/S1751731115000877.

von Keyserlingk, M. A. G., D. Olenick, and D. M. Weary. 2008. Acute behavioral effects of regrouping dairy cows. J. Dairy Sci. 91:10111016. https://doi.org/10.3168/jds.2007-0532.

West, J. W. 2003. Effects of heat-stress on production in dairy cattle. J. Dairy Sci. 86:2131-2144. https://doi.org/10.3168/jds.S0022 -0302(03)73803-X.

West, J. W., B. G. Mullinix, and J. K. Bernard. 2003. Effects of hot, humid weather on milk temperature, dry matter intake, and milk yield of lactating dairy cows. J. Dairy Sci. 86:232-242. https://doi .org/10.3168/jds.S0022-0302(03)73602-9.

Zimbelman, R. B., R. P. Rhoads, M. L. Rhoads, G. C. Duff, L. H Baumgard, and R. J. Collier. 2009. A re-evaluation of the impact of temperature humidity index (THI) and black globe humidity index (BGHI) on milk production in high producing dairy cows. Pages 158-168 in Proc. Southwest Nutr. Man. Conf., Tempe, AZ. University of Arizona, Tucson.

\section{ORCIDS}

Paige V. McDonald ๑ https://orcid.org/0000-0001-5450-1415

Marina A. G. von Keyserlingk (0) https://orcid.org/0000-0002-1427 $-3152$

Daniel M. Weary @ https://orcid.org/0000-0002-0917-3982 